Purdue University Purdue e-Pubs

\title{
A Disinflation Tradeoff: Speed versus Final Destination
}

John A. Carlson

Purdue University

Neven T. Valev

Purdue University

Follow this and additional works at: http://docs.lib.purdue.edu/ciberwp

Carlson, John A. and Valev, Neven T., "A Disinflation Tradeoff: Speed versus Final Destination" (2000). Purdue CIBER Working Papers. Paper 2.

http://docs.lib.purdue.edu/ciberwp/2

This document has been made available through Purdue e-Pubs, a service of the Purdue University Libraries. Please contact epubs@purdue.edu for additional information. 


\title{
A Disinflation Tradeoff: Speed versus Final Destination
}

\author{
by John A. Carlson and Neven T. Valev* \\ Purdue University and Georgia State University
}

\begin{abstract}
$\underline{\text { Abstract }}$
Does a central bank, when introducing a new monetary regime designed to reduce inflation, prefer more or fewer economic agents who form informed forecasts of inflation? The relevance of the question arises because the central bank can make a decision about how much information to disseminate about the nature of the new regime. We find that the central bank will prefer a higher proportion of agents who form rational expectations if it disinflates from a high level of inflation but not so if it disinflates from a moderate or low inflation level.
\end{abstract}

JEL Classification: E58 - Central Banks and Their Policies

*Corresponding author: John A. Carlson, Department of Economics, Krannert Graduate School of Management, Purdue University, West Lafayette, IN 47907. Email:

carlson@mgmt.purdue.edu; Fax: 765-494-9658; Telephone: 765-494-4450.

The authors would like to thank John Barron, Kenneth Matheny, and Cabrielle Camera for their suggestions and comments. We would also like to thank the Center for International Business Education and Research at Purdue University for their financial support. 


\section{A Disinflation Tradeoff: Speed versus Final Destination}

\section{Introduction.}

Whether or not expectations of inflation are rational is an open question. Rational forecasts require knowledge and information that some agents may not find worthwhile acquiring. Instead, since past inflation is a cheap and potentially informative signal about the policies of the central bank, those agents with less information may resort to extrapolation from past inflation to a greater extent than those with more information. In other words, for all agents, expectations have a rational (forward-looking) and an adaptive (backward-looking) component. Differences across agents in terms of information can lead to a separation between those who form more rational and those who form more adaptive expectations. ${ }^{1}$

A simpler heterogeneity -- agents with purely rational or with purely adaptive expectations -- has been adopted in some models. ${ }^{2}$ In that context, when a central bank is the major source of information about monetary policy, it could potentially influence the proportion of agents in each group. A natural question is what are the central bank's preferences regarding the distribution. More specifically, does the central bank prefer many or few agents with rational expectations when introducing a monetary regime designed to reduce inflation?

We will analyze the properties of a Barro-Gordon (1983a) model of monetary policy where some agents form rational and some adaptive expectations. In that setting, a higher proportion of agents with adaptive expectations generally slows down the

\footnotetext{
${ }^{1}$ The notion of "economically rational” expectations introduced by Feige and Pearce (1976) was further examined theoretically by, for example, Sethi and Franke (1995), Crettez and Michel (1992), and empirically by Baghestani (1992).
} 
disinflation process but, as in Sargent (1999), it also allows for a lower long-run inflation rate. An implication of this is that the central bank will prefer a higher proportion of agents who form rational expectations if it disinflates from a high level of inflation but not so if it disinflates from a moderate or low inflation level.

It is generally recognized that expectations do not adjust instantaneously to reflect the new conditions following a change in monetary regime. Instead, agents, including the central bank, observe the unfolding macro developments and form estimates of the parameters that characterize the new environment (Lewis, 1989, Wieland 2000, Mankiw, et al., 1987). A number of interesting questions are addressed in that set-up. What is the speed and correctness of learning? Can the central bank use its control over monetary aggregates to generate observations useful in the learning process, i.e., can learning be an active process? When does equilibrium have an inflationary bias?

The structure of our model is simpler in the sense that the central bank has direct control over inflation and, aside from a random shock, the output response to changes in prices is clear. The simpler set up make the model analytically tractable and allow us to solve explicitly for steady-state inflation and a parameter that captures speed of convergence of inflation to the steady state. We can compare our results with the numerical estimates of other more complicated models, most notably Sargent's (1999). Our explicit solution helps clarify insights about the dynamics of disinflations.

Models of parameter uncertainty and learning have also addressed questions about gradual versus rapid disinflation. With results similar to ours, Balvers and Cosimano (1994) find that rapid disinflation is preferred when inflation is high although in their

\footnotetext{
${ }^{2}$ See for example Haltiwanger and Waldman (1989).
} 
framework rapid reduction in money growth is warranted in order to facilitate learning. In our model, rational agents are preferred since, with high initial inflation, the benefit from rapid disinflation with more rational agents outweighs the cost of higher steady state inflation.

Similar to Cukierman and Meltzer (1986) and Cosimano and Van Huyck (1993), in our model there is a possibility for the central bank to influence the beliefs of the population. The process of expectation formation however is not modeled formally, which contributes substantially to the analytical tractability of the model. We assume that the central bank can publicize its track record with inflation rather than the exact mechanics of its monetary regime, or vice versa. In that way it can influence the relative adaptive (backward-looking) and rational (forward-looking) components of expectations. A brief discussion of our motivation may clarify our thinking about why a central bank might want to influence agents' expectations formation and how it can do so.

The motivation for the paper comes in part from observations of the behavior of the central bank in Bulgaria, where a currency board was introduced on July 1, 1997 . $^{3}$ Orthodox currency boards are fixed exchange-rate regimes that operate like a gold standard except that central-bank reserves are kept in a foreign currency rather than gold. Domestic money is convertible and a monetary aggregate, usually the monetary base, is fully backed by foreign exchange reserves. The central bank, which manages the currency board, has no responsibilities to react to unemployment and no discretionary authority regarding the money supply. These features make a currency board a powerful disinflation device for countries that have had high inflation. To facilitate beliefs that 
disinflation will occur, the central bank will therefore have an incentive to actively advertise what a currency board does.

Most currency boards, however, including the one in Bulgaria, are not entirely orthodox. They have lender of last resort facilities or other features that allow some monetary discretion. Therefore, in practice monetary discretion is limited but not eliminated. If known to the public, these features may raise concerns and contribute to higher expected inflation. It may therefore not be to the advantage of the central bank to advertise all the details about its own currency board.

While a lot of news was disseminated in Bulgaria about the currency board at the time of its introduction, there has not been as much public information since then about how the board operates. The central bank has maintained instead that people should pay attention to the track record with low inflation. ${ }^{4}$ In terms of our model, we will argue that this pattern of behavior makes sense.

The paper is structured as follows. In section 2, we develop the model with two types of agents - those with adaptive expectations and those with rational expectations. Section 3 discusses influences on the dynamics of the inflation process, with emphasis on the effect of having more or fewer naïve agents. Section 4 addresses the issue of what proportion of naïve agents the central bank will choose, if its actions can influence that proportion. Section 5 concludes.

\footnotetext{
${ }^{3}$ For a discussion of the history and operation of currency boards, see Williamson (1995) and Schwartz (1993).

${ }^{4}$ See Carlson and Valev (2000).
} 


\section{A model of monetary policy with heterogeneous agents.}

Output $y_{t}$ (all variables in logarithms) differs from its natural level by an amount determined by the real wage $\left(w_{t}-p_{t}\right)$ :

$$
y_{t}=\bar{y}_{t}-\left(w_{t}-p_{t}\right)-u_{t}
$$

where $u_{t}$ is an i.i.d. supply shock with mean zero and variance $\sigma^{2}$. A positive value of $u_{t}$ represents a negative output shock.

Inflation $\pi_{t}$ is defined by:

$$
\pi_{t}=p_{t}-p_{t-1}
$$

Agents are heterogeneous in the way they form expectations of inflation. A proportion $\theta$ of all agents form adaptive expectations:

$$
E_{t-1}^{A} \pi_{t}=\pi_{t-1}
$$

which yields:

$$
E_{t-1}^{A} p_{t}=p_{t-1}+\pi_{t-1}
$$

The remaining (1- $\theta$ ) agents form rational expectations. Denote their expectations of the price level by $E_{t-1}^{R} p_{t}$.

Before the shock $u_{t}$ has been observed, the nominal wage is set at the average expected price:

$$
w_{t}=\theta\left(p_{t-1}+\pi_{t-1}\right)+(1-\theta) E_{t-1}^{R} p_{t}
$$

Define the monetary authorities' loss function $L_{t}$ as:

$$
L_{t}=\left[y_{t}-\tilde{y}_{t}\right]^{2}+\alpha \pi_{t}^{2}
$$


where $\tilde{y}_{t}$ is the level of output targeted by the policymaker. By substituting (5) into (1) and (1) into (6), we write the loss function as:

$$
L_{t}=\left[\pi_{t}-(1-\theta) E_{t-1} \pi_{t}-\theta \pi_{t-1}-k_{t}-u_{t}\right]^{2}+\alpha \pi_{t}^{2}
$$

where $E_{t-1} \pi_{t}=E_{t-1}^{R} p_{t}-p_{t-1}$ is expected inflation by agents with rational expectations and $k_{t}=\tilde{y}_{t}-\bar{y}_{t}>0$ is the difference between the target and the natural level of output.

After observing the nominal wage and the shock $u_{t}$, the government chooses inflation $\pi_{t}$ to minimize:

$$
V_{t}=\sum_{i=0}^{\infty} \beta^{i} E_{t} L_{t+i}
$$

where $\beta \in[0,1]$. Substitute from (7) into (8) and assume $k_{t+i}=k$, for all $i$. The objective can then be written:

$$
\begin{aligned}
& \min _{\pi_{t}} V_{t}=\min _{\pi_{t}}\left\{\left[\pi_{t}-(1-\theta) E_{t-1} \pi_{t}-\theta \pi_{t-1}-k-u_{t}\right]^{2}+\alpha \pi_{t}^{2}+\right. \\
& \left.+\sum_{i=1}^{\infty} \beta^{i} E_{t}\left[\pi_{t+i}-(1-\theta) E_{t+i-1} \pi_{t+i}-\theta \pi_{t+i-1}-k-u_{t+i}\right]^{2}+\alpha \sum_{i=1}^{\infty} \beta^{i} E_{t} \pi_{t+i}^{2}\right\}
\end{aligned}
$$

Provided that some agents form adaptive expectations $(\theta>0)$, inflation in period $t$ is built into expectations of inflation for period $t+1$ and beyond. Monetary authorities choose inflation to balance their current and future inflation and output objectives.

The first-order condition with respect to $\pi_{t}$, using certainty equivalence, yields:

$$
\beta \theta^{2} E_{t} \pi_{t+1}-\left(1+\alpha+\beta \theta^{2}\right) \pi_{t}+(1-\theta) E_{t-1} \pi_{t}+\theta \pi_{t-1}=-(1-\beta \theta) k-u_{t}
$$

Then taking expectations of both sides of (9) as of time $t-1$ and collecting terms yields the following difference equation:

$$
E_{t-1} \pi_{t+1}-\frac{\alpha+\theta+\beta \theta^{2}}{\beta \theta^{2}} E_{t-1} \pi_{t}+\frac{1}{\beta \theta} \pi_{t-1}=-(1-\beta \theta) \frac{k}{\beta \theta^{2}}
$$


As shown in the Appendix, the solution for (10) can be written:

$$
E_{t-1} \pi_{t}=\lambda \pi_{\mathrm{t}-1}+(1-\lambda) \bar{\pi}
$$

where $\lambda(0<\lambda<1)$ is the smaller root of the characteristic equation and

$$
\bar{\pi}=(1-\beta \theta) \frac{k}{\alpha}
$$

\section{Inflation Dynamics}

In the absence of future shocks, inflation is expected to gradually approach a longrun equilibrium level of $\bar{\pi}$. Note that $\bar{\pi}$ will be lower the higher the proportion $(\theta)$ of naïve agents. The effect is magnified if the central bank places more weight on the expected value of its future losses as indicated by greater values for $\beta$. Intuitively, naïve agents have a "disciplining” effect on the central bank when it considers raising inflation to realize short-run output gains. Higher current inflation is built into the expectations of naïve agents and, thus, implies greater future expected losses to the central bank. ${ }^{5}$ Also, from (12), long-run inflation decreases in the resolve of the monetary authorities to fight inflation (higher $\alpha$ ) and increases in the magnitude of their output objectives (higher $k$ ).

The $\lambda$ parameter is shown in the Appendix to be:

$$
\lambda=\frac{\alpha+\theta+\beta \theta^{2}-\sqrt{\left(\alpha+\theta+\beta \theta^{2}\right)^{2}-4 \beta \theta^{3}}}{2 \beta \theta^{2}}
$$

The anticipated speed of adjustment toward the long run inflation rate is given by (1- $\lambda$ ) or, put differently, the degree of persistence in inflation is given by $\lambda$. We are interested

\footnotetext{
${ }^{5}$ Note that without naive agents $(\theta=0)$ or with a myopic policymaker $(\beta=0)$, long run inflation is $k / \alpha$, the solution to a one-period Barro-Gordon problem. This result is similar to earlier papers where the existence of a "punishment mechanism" or credibility considerations support lower steady state inflation compared to the one-shot game. See for example Barro-Gordon (1983b) and Rogoff (1987).
} 
in the effect of the resolve of the central bank to fight inflation $(\alpha)$, the discount factor $(\beta)$, and the proportion of naïve agents $(\theta)$ on this inflation persistence.

First, note that $\lambda$ is a decreasing function of $\alpha$. The greater the relative weight that the central bank puts on inflation in its objective function, the more rapidly it will try to bring down inflation to the long-run level, as well as having a lower long-run inflation target.

A similar intuition applies to the fact that $\lambda$ is a decreasing function of $\beta$. If the monetary authority puts relatively more weight on future losses, it wants to get high inflation out of the system more quickly.

We also find that $\lambda$ is generally an increasing function of $\theta$. A higher proportion of naïve agents slows down the speed of adjustment and adds to the persistence of inflation. This result, coupled with the effect of $\theta$ on the long-run inflation rate, gives rise to a tradeoff for the central bank between rapid disinflation and lower long-run inflation. ${ }^{6}$ This is discussed more fully below.

Next we consider briefly how responsive the monetary authority in this framework is to a supply shock. As shown in the Appendix, current inflation is:

$$
\pi_{t}=\lambda \pi_{t-1}+(1-\lambda) \bar{\pi}+\frac{1-\beta \lambda^{2}}{1+\alpha-\beta \lambda^{2}+\beta \theta^{2}(1-\lambda)^{2}} u_{t}
$$

The coefficient on $u_{t}$ is unambiguously positive, so that a negative shock to output will call for an increase in inflation. How large that response will be depends on the

\footnotetext{
${ }^{6}$ Numerical analysis indicates that when $\beta$ is high, $\lambda$ as a function of $\theta$ may reach a peak at high values of $\theta$ and then decrease slightly. Intuitively, with high $\beta$, the costs in future periods from not reducing inflation now may outweigh the persistence effect of marginally higher $\theta$.
} 
parameters $\alpha, \beta$, and $\theta$. A greater proportion of naïve agents will generally decrease the inflation response to a supply shock as high current inflation is built into future expectations.

\section{Preferences of the central bank over the distribution of agents.}

We now address the question about whether the central bank with a mandate to generate disinflation has any preference regarding the distribution of agents in the two groups -- with rational and with adaptive expectations at the time it introduces the new policy. In particular, the bank may choose to engage in more or less dissemination of information about the features and implications of the new regime. Formally, ignoring any current supply shock, we write the objective function as (see Appendix):

$$
\begin{aligned}
& W_{t}=\left[\pi_{t}-(\lambda-\lambda \theta+\theta) \pi_{t-1}-(1-\lambda)(1-\theta) \pi_{t}-k\right]^{2}+\alpha \pi_{t}^{2}+ \\
& \left.+\sum_{j=1}^{\infty} \beta^{j}\left\{\theta(\lambda-1) \lambda^{j-1}\left(\pi_{t}-\bar{\pi}\right)-k\right]^{2}+\alpha\left[\lambda^{j} \pi_{t}+\left(1-\lambda^{j}\right) \bar{\pi}\right]^{2}\right\}
\end{aligned}
$$

We are interested in what value of $\theta$ minimizes (12) given the bank's preferences, reflected in the $\alpha, \beta$ and $\mathrm{k}$ parameters, and the prior level of inflation $\pi_{t-1}$.

Figures 1, 2 and 3 show three examples in which the objective function (12) is calculated for $\theta$ in the interval between 0 and 1 . In all examples $\beta=0.9, \alpha=0.2$ and $\mathrm{k}=$ 1 , so that new long term-inflation in the absence of naïve agents (with $\theta=0$ ) would be 5 . $^{7}$ We calculated the objective function with three different values for $\pi_{\mathrm{t}-1}$ chosen to proxy for high, moderate and low inflation. In Figure $1, \pi_{\mathrm{t}-1}=30$ (high compared to equilibrium inflation with no naïve agents), in Figure 2, $\pi_{\mathrm{t}-1}=15$ (“moderate" but still higher than

\footnotetext{
${ }^{7}$ Steady state inflation with rational agents equal to 5 is the same as the Nash equilibrium inflation in Sargent (1999, page 84). Replacing rational with adaptive expectations and with a discount factor of .97, Sargent (1999) reports equilibrium inflation of 1.57 . In our calibrations, with $\theta=1$, i.e., only adaptive
} 
equilibrium inflation with no naïve agents), and in Figure $3, \pi_{\mathrm{t}-1}=5$ (equal to equilibrium inflation with no naïve agents).

When authorities want to minimize the objective function (12), the figures deliver an ambiguous message that it depends on where the economy starts. Figure 1 indicates that if the economy starts at a very high inflation rate, the objective function is minimized by having very few naive agents. This is because with very few naive agents substantial progress can be made early in bringing down inflation and those early declines outweigh the costs of higher long-run inflation. In this case, there should be a lot of information about the new regime so that more agents can more rationally take into account how the regime will achieve a disinflation.

At the other extreme if initial inflation is already fairly low, the objective function is minimized by having a high proportion of naive agents as depicted in Figure 3. In that case, the gains in reducing long-run inflation outweigh the loss in bringing inflation down less rapidly, and the authorities may want to withhold information hoping that most agents will form their expectations as a simple extrapolation of what has been most recently observed. The intermediate case, as in Figure 2, suggests that with moderate initial inflation the optimal solution is to have a mix of both naive and rational agents.

\section{Discussion.}

A stylized fact about inflation stabilization has been a pattern of rapid declines in inflation from high to moderate levels but slow convergence from moderate to low levels. In fact, the episodes of rapid disinflation documented by Sargent (1982) are explained by rational expectations, while the episodes of real exchange-rate appreciation summarized 
by Calvo and Vegh (1994) are often explained by persistence in expectations. In our variation of the Barro-Gordon model, when the central bank initiates a new disinflation policy, more informed (rational) agents are desirable because they increase the rate of disinflation but are undesirable to the extent that they contribute later to a stubborn persistence of lower inflation when output targets exceed the natural rate of output.

These implications suggest that a central bank faced with the task of disinflating from a high rate of inflation would want to provide substantial information about the new disinflation policy at its inception and then gradually withdraw from public discussion as inflation declines. This appears to be what has been happening in Bulgaria. At the introduction of the Bulgarian currency board, policymakers were engaged significantly in explaining how a currency board works and what it has done for other countries. Once inflation was lower, policymakers began instead referring to the track record with low inflation rather than explaining how low inflation comes about or what policies it has at its disposal. As we pointed out earlier, a possible reason is that the design of the currency board in Bulgaria, as that of most other currency boards, allows some discretion over monetary policy. One example is the facilities for liquidity to the banking system. Understanding of the balance sheet of the central bank may raise concerns and, respectively, expected inflation on the part of rational agents.

In terms of the model, one could argue that, if the distribution of agents is a choice variable for the central bank in each period, such information should be incorporated in the expectations of rational agents. A switch in the extent of information from more to less over time, if anything however, helps the disinflation policy. This is because rational

Sargent's discount factor of .97, steady state inflation is 0.15 . 
agents who anticipate that there will be relatively more naïve agents in the future will expect inflation to fall even more than if there were no change in the proportions of naïve and rational agents. 


\section{References}

Baghestani, Hamid (1992). “On the Formation of Expected Inflation under Various Conditions: Some Survey Evidence.” Journal of Business, 65, 281-293.

Barro, Robert, and David Gordon (1983a). "A Positive Theory of Monetary Policy in a Natural Rate Model,” Journal of Political Economy 91(4), August: 589-610.

Barro, Robert, and David Gordon (1983b). "Rules, Discretion, and Reputation in a Model of Monetary Policy,” Journal of Monetary Economics 12, July: 101-21.

Balvers, Ronald and Thomas Cosimano (1994). "Inflation Variability and Gradualist Monetary Policy”, Review of Economic Studies, 61, 721-738.

Calvo, Guillermo and Carlos Vegh (1994). “Inflation Stabilization and Nominal Anchors.” Contemporary Economic Policy XII, April: 35-45.

Carlson, John and Neven Valev (2001). "Credibility of a New Monetary Regime: The Currency Board in Bulgaria” Journal of Monetary Economics, 47(3), June.

Cosimano, Thomas and John B. Van Huyck (1993). "Central Bank Secrecy, Interest Rates, and Monetary Control”, Economic Inquiry, July, 370-382.

Crettez, Bertrand and Philippe Michel (1992). "Economically Rational Expectations Equilibrium.” Economics Letters 40: 203-206.

Cukierman, Alex and Allan Meltzer (1986). “Theory of Ambiguity, Credibility, and Inflation under Discretion and Asymmetric Information” Econometrica 54(5), September: 1099-1128.

Feige, Edgar and Douglas Pearce (1976). “Economically Rational Expectations: Are Innovations in the Rate of Inflation Independent of Innovations in Measures of Monetary and Fiscal Policy?” Journal of Political Economy, v84 n3 (June), pp. 499-522.

Haltiwanger, John and Michael Waldman (1989). "Limited Rationality and Strategic Complements: The Implications for Macroeconomics.” Quarterly Journal of Economics, August, 463-483.

Lewis, Karen (1989). "Changing Beliefs and Systematic Rational Forecast Errors with Evidence from Foreign Exchange”, American Economic Review, September, 621-636.

Mankiw, Gregory, Jeffrey Miron, and David Weil (1987). “The Adjustment of Expectations to a Change in Regime: A Study of the Founding of the Federal Reserve”, American Economic Review 77, 358-374. 
Rogoff, Kenneth (1987). "Reputational Constraints on Monetary Policy.” CarnegieRochester Conference Series on Public Policy 26, Spring, 141-81.

Sargent, Thomas J. (1982). “The Ends of Four Big Inflations” in Inflation: Causes and Effects, R. E. Hall, ed., University of Chicago Press: Chicago.

Thomas J. Sargent (1999). The conquest of American Inflation. Princeton, N.J. : Princeton University Press.

Schwartz, Anna J (1993), “Currency Boards; Their Past, Present and Possible Future Role”, Carnegie-Rochester Conference Series on Public Policy 39, 147-187.

Sethi, Rajiv and Reiner Franke (1995). "Behavioral Heterogeneity Under Evolutionary Pressure: Macroeconomic Implications of Costly Optimization.” The Economic Journal, 105: 583-600.

Wieland, Volker (2000). "Monetary Policy, Parameter Uncertainty and Optimal Learning”, Journal Of Monetary Economics (46)1, pp. 199-228.

Williamson, John (1995). What Role for Currency Boards? (Institute for International Economics, Washington). 
Figure 1. Value function, high inflation

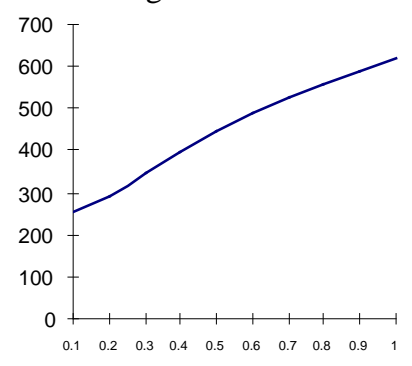

Proportion of naive agents
Figure 2. Value function, moderate inflation

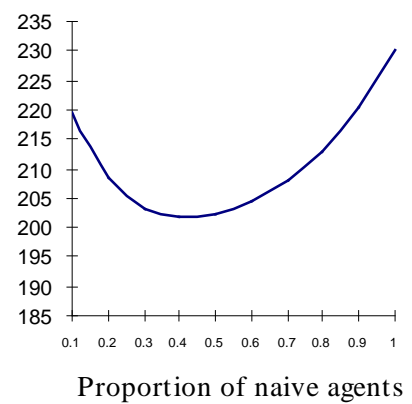

Figure 3. Value function, low inflation

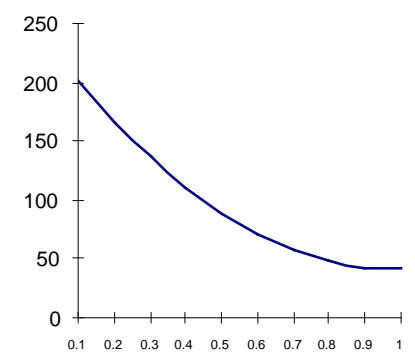

Proportion of naive agents 


\section{Appendix}

In the absence of any shocks, the first-order condition can be written as the following second-order difference equation:

$$
\pi_{\mathrm{t}+1}-\frac{\alpha+\theta+\beta \theta^{2}}{\beta \theta^{2}} \pi_{\mathrm{t}}+\frac{1}{\beta \theta} \pi_{\mathrm{t}-1}=-(1-\beta \theta) \frac{k}{\beta \theta^{2}}
$$

or in lag-operator notation:

$$
\left(1-\lambda_{1} \mathrm{~L}\right)\left(1-\lambda_{2} \mathrm{~L}\right) \pi_{\mathrm{t}+1}=-(1-\beta \theta) \frac{k}{\beta \theta^{2}}
$$

where $\lambda_{1}$ and $\lambda_{2}$ are the roots of the characteristic equation

$$
\mathrm{f}(\lambda)=\left(\lambda-\lambda_{1}\right)\left(\lambda-\lambda_{2}\right)=\lambda^{2}-\frac{\alpha+\theta+\beta \theta^{2}}{\beta \theta^{2}} \lambda+\frac{1}{\beta \theta}=0
$$

Note that

$$
\begin{aligned}
& f(0)=\frac{1}{\beta \theta}>0 \\
& f(1)=\left(1-\lambda_{1}\right)\left(1-\lambda_{2}\right)=-\frac{\alpha}{\beta \theta^{2}}<0
\end{aligned}
$$

These imply that the smaller root lies between 0 and 1 and the larger root is greater than 1. The smaller root can be written explicitly as

$$
\lambda_{1}=\frac{\alpha+\theta+\beta \theta^{2}-\sqrt{\left(\alpha+\theta+\beta \theta^{2}\right)^{2}-4 \beta \theta^{3}}}{2 \beta \theta^{2}}
$$

One can use (A.4) and (A.5) to show that an increase in $\alpha$, with $0<\theta<1$, lowers $\lambda_{1}$. A numerical analysis establishes that an increase in $\beta$ also lowers $\lambda_{1}$.

If one multiplies (A.2) through by $\left(1-\lambda_{2} L\right)^{-1}$, the result assuming no bubbles is:

$$
\left(1-\lambda_{1} \mathrm{~L}\right) \pi_{\mathrm{t}+1}=\frac{1-\beta \theta}{\lambda_{2}-1} \frac{k}{\beta \theta^{2}}
$$

Then after substituting for $\left(\lambda_{2}-1\right)$ from (A.5):

$$
\pi_{\mathrm{t}+1}=\lambda \pi_{\mathrm{t}}+(1-\lambda) \bar{\pi}
$$


where $\lambda=\lambda_{1}$ and

$$
\bar{\pi}=(1-\beta \theta) \frac{k}{\alpha} .
$$

(A.7) also implies that

$$
\begin{aligned}
& \mathrm{E}_{\mathrm{t}-1} \pi_{\mathrm{t}}=\lambda \pi_{\mathrm{t}-1}+(1-\lambda) \bar{\pi} \text { and } \\
& \mathrm{E}_{\mathrm{t}} \pi_{\mathrm{t}+\mathrm{n}}=\bar{\pi}+\lambda^{n}\left(\pi_{\mathrm{t}}-\bar{\pi}\right)
\end{aligned}
$$

Given the quadratic objective function, we can use certainty equivalence and rewrite the objective function as:

$$
\begin{aligned}
& \min _{\pi_{t}} W_{t}=\left[\pi_{t}-(1-\theta) E_{t-1} \pi_{t}-\theta \pi_{t-1}-k-u_{t}\right]^{2}+\alpha \pi_{t}^{2} \\
& +\sum_{i=1}^{\infty} \beta^{i}\left[\theta E_{t} \pi_{t+i}-\theta E_{t} \pi_{t+i-1}-k\right]^{2}+\alpha \sum_{i=1}^{\infty} \beta^{i} E_{t} \pi_{t+i}^{2}
\end{aligned}
$$

Substituting from (A.9) and (A.10) into (A.11), we have:

$$
\begin{aligned}
& W_{t}=\left[\pi_{t}-(\lambda-\lambda \theta+\theta) \pi_{t-1}-(1-\lambda)(1-\theta) \pi_{t}-k-u_{t}\right]^{2}+\alpha \pi_{t}^{2}+ \\
& +\sum_{j=1}^{\infty} \beta^{j}\left\{\left[\theta(\lambda-1) \lambda^{j-1}\left(\pi_{t}-\bar{\pi}\right)-k\right]^{2}+\alpha\left[\lambda^{j} \pi_{t}+\left(1-\lambda^{j}\right) \bar{\pi}\right]^{2}\right\}
\end{aligned}
$$

Take the derivative of $\mathrm{W}_{\mathrm{t}}$ with respect to $\pi_{\mathrm{t}}$ and set it equal to zero:

$$
\begin{aligned}
& \partial W_{t} / \partial \pi_{t}=2\left[\pi_{t}-(\lambda-\lambda \theta+\theta) \pi_{t-1}-(1-\lambda)(1-\theta) \bar{\pi}-k-u_{t}\right]+2 \alpha \pi_{t}+ \\
& \left.+\sum_{j=1}^{\infty} \beta^{j}\left\{\theta\left(\lambda^{j}-\lambda^{j-1}\right)\left(\pi_{t}-\bar{\pi}\right)-k\right] \theta\left(\lambda^{j}-\lambda^{j-1}\right)+\alpha\left[\lambda^{j} \pi_{t}+\left(1-\lambda^{j}\right) \bar{\pi}\right] \lambda^{j}\right\}=0
\end{aligned}
$$

Differentiate (A.13) totally with respect to $\pi_{t}$ and $u_{t}$ to see how the optimal $\pi_{t}$ varies in response to $\mathrm{u}_{\mathrm{t}}$. As a result we have:

$$
\frac{\partial \pi_{t}}{\partial u_{t}}=\frac{1-\beta \lambda^{2}}{\left(1-\beta \lambda^{2}\right)(1+\alpha)+\alpha \beta \lambda^{2}+\beta \theta^{2}(1-\lambda)^{2}}
$$

Hence,

$$
\pi_{t}=\lambda_{1} \pi_{t-1}+\left(1-\lambda_{1}\right) \bar{\pi}+\frac{1-\beta \lambda^{2}}{1+\alpha-\beta \lambda^{2}+\beta \theta^{2}(1-\lambda)^{2}} u_{t}
$$

